\title{
MIGUEL ÁNGEL MAQUERA, PINTOR DEL MOJINETE
}

\author{
Miguel Angel Maquera, Painter of coping
}

\author{
Arturo Toledo Gonza ${ }^{1}$
}

\begin{abstract}
RESUMEN
El artículo trata sobre la vida y obra del pintor Miguel Ángel Maquera Maquera. En la década de los años 60 a 80 en que desarrolló una técnica de pinturas al esmalte, al óleo y técnicas mixtas, desenvolviéndose con gran maestría en el tema de los paisajes tacneños resaltando las antiguas casas con techo mojinete y sus famosas tinajas. La proficua producción hizo que participara en diferentes exposiciones a nivel nacional e internacional.
\end{abstract}

Palabras claves: paisaje, mojinete, esmalte, Tacna, tinaja

\begin{abstract}
The article is about the life of the talented painter Miguel Angel Maquera Maquera, approximately in the decade of the 60-80 when he developed a series of paintings with the enamel technique, oil painting and mixed techniques unfolding with great expertise on the subject of tacneños slanted roof landscapes, its famous jars and the different exhibitions performed at national and international level
\end{abstract}

Keywords: landscape, slanted, enamel, Tacna, jar.

\section{INTRODUCCIÓN}

El paisaje como tema es muy dinámico a su vez plástico y, abundantemente, colorista. Representa escenas de la naturaleza, cielos, montañas, árboles, ríos. Desde siglos atrás la pintura del paisaje fue adquiriendo poco a poco preeminencia. Se han plasmado en diferentes soportes y lienzos en diferentes épocas y lugares del planeta.

El presente trabajo tiene como propósito describir la pintura del artista Miguel Ángel Maquera Maquera y conocer su vida, las obras, además, valorar el material utilizado y sus diferentes componentes en el tema.

El paisaje tacneño como motivo, las famosas casonas con techo de mojinete reivindicadas en la artes plásticas por Miguel Ángel Maquera, su trabajo resulta un ejemplo a seguir para los futuros artistas. Su pincelada está cargada con una gama atmosférica de colores pasteles y sus cielos grises dan vida a una pintura simbólica, las casas con sus peculiares estructuras, de la misma manera sus tinajas y buganvilias adornan el paisaje tacneño.

${ }^{1}$ Licenciado en Arte. Docente de la Facultad de Ingeniería Civil, Arquitectura y Geotecnia de la Universidad Nacional de Jorge Basadre Grohmann. Tacna-Perú.

Correoelectrónico:azul.mipensamiento@hotmail.com 


\section{Breve biografía}

Miguel Ángel Maquera Maquera nació en la ciudad de Ilave de la región de Puno, en el año 1950. Sus estudios de primaria y secundaria lo realiza en dicha ciudad, posteriormente se traslada a Tacna.

Estudió pintura y grabado en la casa de la cultura de Tacna, también realizó estudios en la Facultad de Bellas Artes de la Universidad de Santiago de Chile y posteriormente viaja con una beca a Cuernavaca, México, para un curso de restauración.

\section{La vida y la pirotecnia de su paleta}

El maestro pintó con gran pasión. Los colores de sus cuadros eran verdaderas explosiones de luz, intensidad y contraste. Podemos decir, según Newton, "los artistas pintan con pigmentos que pueden reproducir los mismos colores de la luz, dado que los colores luz y los de la paleta coinciden, es fácil para el artista imitar los efectos de la luz y reproducir exactamente todo los colores de la naturaleza" (Parramon, 2010).

Dignamente Miguel Ángel trato de aplicar todo ese conocimiento y el uso correcto de los colores. Amplía formidablemente los sucesos formales de la paleta del artista a la hora de captar matices y calidades de la luz y su color.

Hablar del encanto de los colores que transitó en las obras de Miguel Ángel es hablar de una Tacna que se va en el tiempo. Nada está dicho aún sobre este grandioso artista. Hay mucho que hablar sobre él y su obra. Marcó un antes y después en la pintura tacneña. Cuenta la historia que era un pintor de la mano surda, diestro en realizar sus pinturas, minucioso con la forma y los detalles. Tenía un horario especial, como todo artista, en realizar sus obras. La mayor parte fueron concebidas de noche, en su pequeño recinto y por el día salía a ven- der sus pinturas por el centro de la ciudad. Vestía, la mayor parte, con un traje de saco beis muy alegre y desafiante a la vida misma en si por el mismo hecho de sobrevivir del arte en una sociedad poco ajena al consumo de la pintura y mucho más en esos tiempos. Vivía alquilado y esporádicamente se trasladaba siempre como un errante junto con su amada esposa Maruja Ramos y sus tres hijos el pequeño Miguel Ángel, Carmen y Mary.

Fue uno de los primeros artistas que dio a conocer en sus cuadros las viviendas construidas con techo de mojinete allá por los tardíos años 90. Al inicio su paleta era gris, pero al pasar el tiempo iba en halagüeña maduración y posteriormente empezaron a florecer sus colores llegando a dominar con gran maestría la técnica del esmalte, un material industrial utilizado normalmente para la publicidad, de la misma manera la pintura al óleo.

Realizó su muestra individual en Tacna en el año de 1987, titulada la "Tacna que se va" donde presento las fabulosas casonas de Tacna. Posteriormente por el año 90, es invitado por Carlos Herrera Burgos y la colonia peruana para realizar una muestra pictórica en New York, en el recordado famoso edificio de las torres gemelas (World Center) allí expuso una serie de pinturas del paisaje de Sama. En cuanto a la venta de sus pinturas, a medida que crecía su popularidad también subía sus precios, hasta llegar a vender en dólares. A finales del año 2005, repentinamente le llega la muerte, fallese un día domingo, para ser exactos, un 27 de noviembre del 2005 tuvo una expiración irónica. El destino ya estaba marcado en su vida.

Recibió varias distinciones. Sus obras se encuentran en colecciones particulares y privadas en: EE.UU. Venezuela, Chile, Argentina, Bolivia, México y Perú. También en familias de la alta y 
mediana clase social y en las paredes humildes de los suburbios. Pasa a ser un mito hasta hoy su vida y sus excesos en la bohemia y la pintura.

\section{El Mojinete}

La construcción arquitectónica de las casas con techo de mojinete en la ciudad de Tacna como en otros lugares es muy peculiar. La forma de elaboración, los primeros estilos constructivos y arquitectónicos se mencionan en el texto de Luis Cavagnaro quien al respecto precisa "como las primeras edificaciones de adobe que se levantaron, dentro del ámbito de la reducción o en las incipientes áreas de expansión, debieron estar rodeadas de huertas y sus frontis inmediatos a las proyectadas calles; es muy probable que contaran con un cobertizo delante de la puerta principal."

Con el mejoramiento de la vivienda se incluyeron una o dos habitaciones a uno y otro lado del cobertizo quedando un conjunto arquitectónico con planta en forma de " $\mathrm{U}$ ".

Las mejoras inmediatas debieron estar orientadas al referido cobertizo: empedrado del piso con baldosas de piedra de canterías finamente talladas y, en el contorno de este ambiente, con la construcción de escaños de piedra denominadas "poyos" o "patillas" (Cavagnaro, 2010).

De la misma manera podemos citar el texto de Luis Montenegro Vargas, quien se ocupa de la tipología de vivienda tacneña en el siglo XIX, y detalla como sigue "de la función: estructura de pertenencia predominantemente de uso íntimo y de concentración, con una expansión de servicio. Del estilo: de un solo nivel con forma regular y simétrica; con cobertura de techo mojinete. De los materiales constructivos: cimentación de piedra, muros de adobe y quincha, cobertura de torta de barro - estructura de madera y carrizo, pisos entablonados de madera" (Montenegro, 2010).

\section{La técnica del esmalte}

El esmalte como material sintético y a su vez, como alternativa de pigmento artístico, tiene un difícil manejo técnico por sus componentes químicos y de secado rápido. Los esmaltes pueden aplicarse en diferentes espacios y soportes como por ejemplo en madera, paneles de fibra, lienzo, cartón etc. Es un material poco utilizado por los artistas en lienzo, pero fue dominada con gran destreza por Miguel Ángel.

"Los esmaltes secan para formar una película compacta, elástica, relativamente duradera y ópticamente estable. Los esmaltes de fabricación industrial, utilizados con los disolventes adecuados, pueden encontrase en varios tonos, haciendo innecesario prepararlos manualmente. Los esmaltes sintéticos, con una base de resina alquídica, se diluyen con disolventes orgánicos y se secan por oxidación de la película de barniz" (Ludvik, 1990).

\section{Análisis y descripción de sus obras}

Podemos observar en sus pinturas los diferentes períodos $\mathrm{y}$, del mismo modo, la influencia de otros artistas y corrientes pictóricas como el figurativo, la abstracción y el expresionismo, así como la presencia de los pintores Oswaldo Guayasamin, Víctor Turpo, entre otros.

La armonía cromática empleada en sus pinturas lo conforman gamas intermedias de colores cálidos y fríos entre súperposiciones de pigmento.

La composición empleada está distribuida armónicamente por todos los elementos, dando a cada uno la importancia que se merece, como las casonas, arboles, tinajas, cielos y las piedras etc. 
También podemos destacar el contraste que utilizó en sus pinturas. Se da mediante los elementos de la luz, sombra, línea, formas, texturas, tonos y colores opuestos, que busca para destacar elementos dominantes en el cuadro.

La atmósfera, que es muy importante en su obra, causa la sensación de espacio en el espectador.

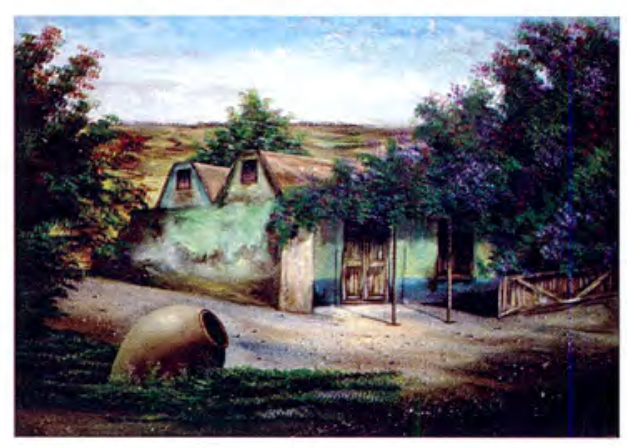

Figura 1. Casona tacneña

Colección privada de Sabino Maquera

Fichaje de la Obra

Técnica: Óleo sobre lienzo

Medidas: $65 \mathrm{~cm} \times 45 \mathrm{~cm}$

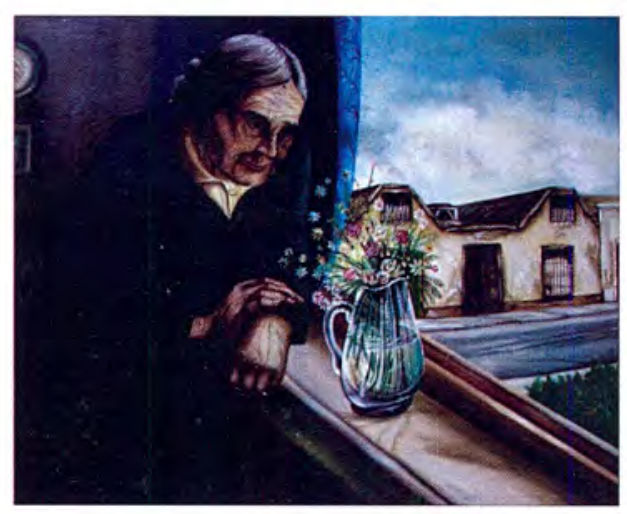

Figura 3.. Añoranzas en el atardecer

Colección privada de Alfonso roca

Fichaje de la Obra

Técnica: Óleo sobre lienzo

Medidas: $40 \mathrm{~cm} \times 50 \mathrm{~cm}$
Un detalle peculiar en sus cuadros una vez culminada la obra pictórica, el artista firmaba del lado contrario, en vez de Maquera - areuqaM.

Se involucra con la sociedad con el fin de vender sus obras y mediante ellas despertar sentimientos, emociones $y$ reflexiones.

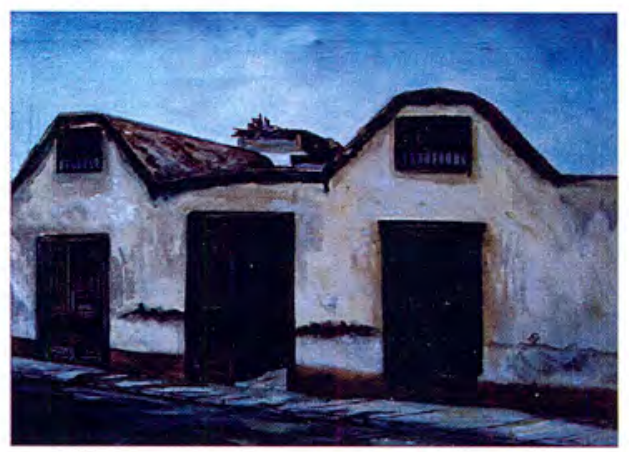

Figura 2. Casona con techo mojinete

Colección privada de Alfonso Roca

Fichaje de la Obra

Técnica: Esmalte sobre lienzo

Medidas: $45 \mathrm{~cm} \times 53 \mathrm{~cm}$

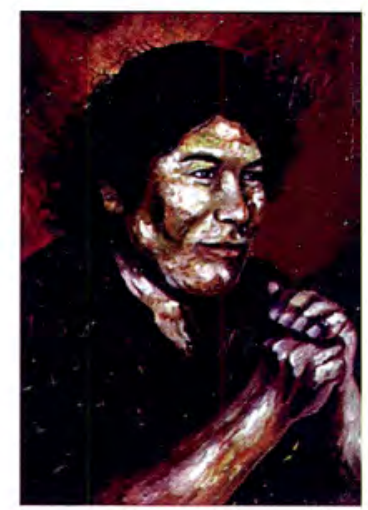

Figura 4. Retrato al Poeta

Colección privada de Sabino Maquera

Fichaje de la Obra

Técnica: Óleo sobre lienzo

Medidas: $20 \mathrm{~cm} \times 35 \mathrm{~cm}$ 


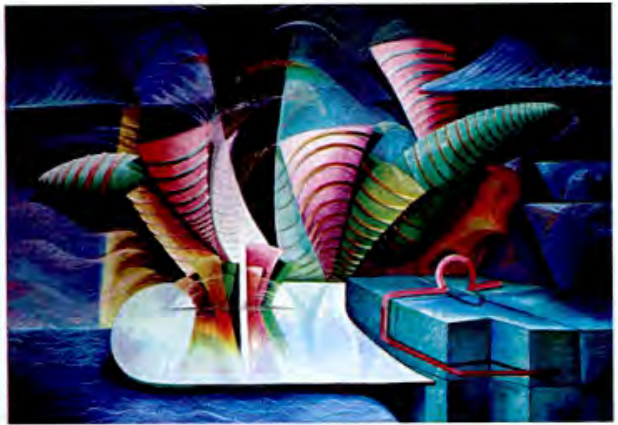

Figura 5. Geometría Cromática

Colección privada de Sabino Maquera

Fichaje de la Obra

Técnica: Óleo sobre lienzo

Medidas: $120 \mathrm{~cm} \times 95 \mathrm{~cm}$

\section{Exposiciones Pictóricas}

1988: Exposición Pictórica en el World Trade Center. EEUU.

1995: Exposición Pictórica, Casa Zela Tacna-Perú.

1993: Exposición Colectiva consulado de Chile. Tacna-Perú.

1985: Exposición Pictórica, Galería del Banco Industrial de Tacna-Perú.

1983: Homenaje a Tacna, galería del banco industrial Tacna-Perú.

1981: Exposición Pictórica, Homenaje a Jorge Basadre, hotel de turista de Tacna-Perú.

1980: Exposición Pictórica, Casa Basadre. Tacna-Perú.

1979: Exposición Pictórica MaracaiboVenezuela.

1978: Casa Guayasamin, QuitoEcuador.

1978: Muestra Plástica Museo de Arte Contemporáneo Santiago-Chile.

1977: Exposición Pictórica Galería Alianza Francesa-Lima-Perú

1977: Muestra Plástica Buenos Aires y Mendoza-Argentina.

1977: Exposición Pictórica Casa de la Cultura Nuñoa Santiago-Chile.
1976: Exposición Pictórica ValparaísoChile.

1976: Muestra Plástica, galería Imagen, Santiago-Chile.

1975: Exposición Pictórica, Sala Ercila, Antofagasta-Chile.

1974: Exposición Pictórica, Homenaje al Perú Arica-Chile.

1973: Exposición Pictórica, Casino de Arica-Chile.

1972: Exposición Pictórica, Casa de la Cultura-Tacna-Perú.

\section{ASÍ SE DESPIDIÓ MIGUEL ÁNGEL MAQUERA}

Tacna, ya no te robaré

Tus albas azules ni tus ojos grises

Ni tus verdes vilcas, ni jacarandas

Hermosa combinación de tinaja y casonas

Salas elegantes de cuadros y risas fantasmales

De una "Tacna que se va"

Con mojinete o sin mojinete

No puedo salvarte como Cusco o Lima

Puedo pintarte al vuelo del colibrí

Te quedas como el lienzo como pienso

Con tu cielo y campiña

El Intiorko dejo a mi madre

En el Arunta dejo mi vida alegre

De esa risa que lo heredé de tu vino

$Y$ alegría pintada por mis manos

Mis lindos pinceles del amanecer

Mis lindos óleos del anochecer

Y mis esmaltes juguetones

Tacna, tú te quedas yo me voy

La luna de Sobraya está lejana

El retorno no tiene regreso

Un artista es único, un cometa viajero

Que deja su luz multicolor

Remolinos del ande bajan 
Me envuelven en sus circunferencias Los caballos de oro vuelan y chispean ¡A dios!

Tierra siena, coronas del santo de nieve resplandecen en esta noche

Sabino Maquera Cotrado
Poeta
19-10-2015

\section{Exponen obras de Miguel Ángel Maquera}

Textos: Epensa web@grupoepensa.pe Fuente: diario correo 05 de diciembre del 2009-08:25 | Tacna

Once pinturas del extinto artista tacneño Miguel Ángel Maquera forman parte de la exposición pictórica "Reencuentros 2", que fue inaugurada ayer en las instalaciones de la Casa Zela. Dicha muestra está integrada por un total de 30 cuadros $\mathrm{y}$ tres esculturas que pertenecen a artistas locales como René Alanoca, Orlando Roque, Fredy Arizaca, Isaac Páucar, Arturo Toledo, Raúl Velarde, Javier Jaramillo, Juana Elizalde, Alfonso Roca, entre otros. Todos ellos se han unido para rendir homenaje al fallecido artista plástico, cuyo cuarto aniversario de deceso se conmemoró el pasado 27 de noviembre. A la inauguración de la muestra acudió la esposa de Miguel Ángel Maquera, María Ramos, quien recordó que este se inició pintando cuadros indigenistas para luego pasar a los paisajes, tema con el que es identificado actualmente. En sus últimos años, Miguel Ángel comenzó a pintar interiores de viviendas y bodegones, precisó Evelin Aguilar.

\section{REFERENCIAS BIBLIOGRÁFICAS}

Cavagnaro, O. L. (2010). Tacna: Desarrollo Urbano y Arquitectónico (15361880). Tacna-Perú: Editor Céticos.

Montenegro, V. L. (2010). Estudio Tipológico de la vivienda tacneña. TacnaPerú: Colegio de Arquitectos de Perú-Regional.

Parramon. (2010). Curso Completo de Dibujo y Pintura. BarcelonaEspaña: Ediciones S.A.

Ludvik, L. (1990). Las técnicas de la pintura. Madrid-España: Ediciones Libsa.

http://diariocorreo.pe/media/thumbs /uploads/articles/images/expo nen-obras-de-miguel-angelmaquera-17282 (Consulta: 19 octubre 2015) 